
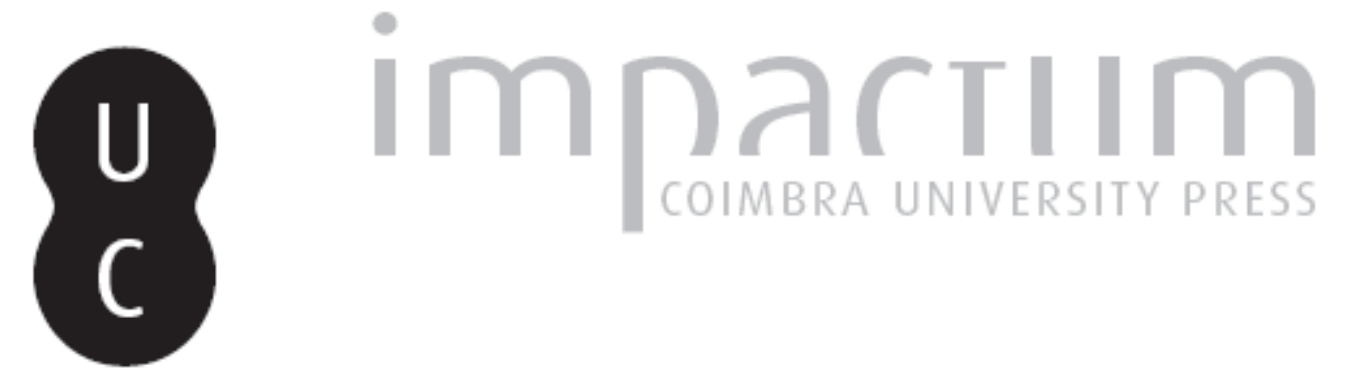

\title{
Lusofonia em perspectiva: panlusitanismo, lusobrasileirismo e lusotropicalismo
}

Autor(es): $\quad$ Skolaude, Mateus Silva; Paredes, Marçal de Menezes

Publicado por: Imprensa da Universidade de Coimbra

URL persistente:

URl:http://hdl.handle.net/10316.2/43248

DOI:

DOI:https://doi.org/10.14195/0870-4147_48_12

Accessed : $\quad$ 26-Apr-2023 09:32:00

A navegação consulta e descarregamento dos títulos inseridos nas Bibliotecas Digitais UC Digitalis, UC Pombalina e UC Impactum, pressupõem a aceitação plena e sem reservas dos Termos e Condições de Uso destas Bibliotecas Digitais, disponíveis em https://digitalis.uc.pt/pt-pt/termos.

Conforme exposto nos referidos Termos e Condições de Uso, o descarregamento de títulos de acesso restrito requer uma licença válida de autorização devendo o utilizador aceder ao(s) documento(s) a partir de um endereço de IP da instituição detentora da supramencionada licença.

Ao utilizador é apenas permitido o descarregamento para uso pessoal, pelo que o emprego do(s) título(s) descarregado(s) para outro fim, designadamente comercial, carece de autorização do respetivo autor ou editor da obra.

Na medida em que todas as obras da UC Digitalis se encontram protegidas pelo Código do Direito de Autor e Direitos Conexos e demais legislação aplicável, toda a cópia, parcial ou total, deste documento, nos casos em que é legalmente admitida, deverá conter ou fazer-se acompanhar por este aviso.

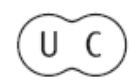




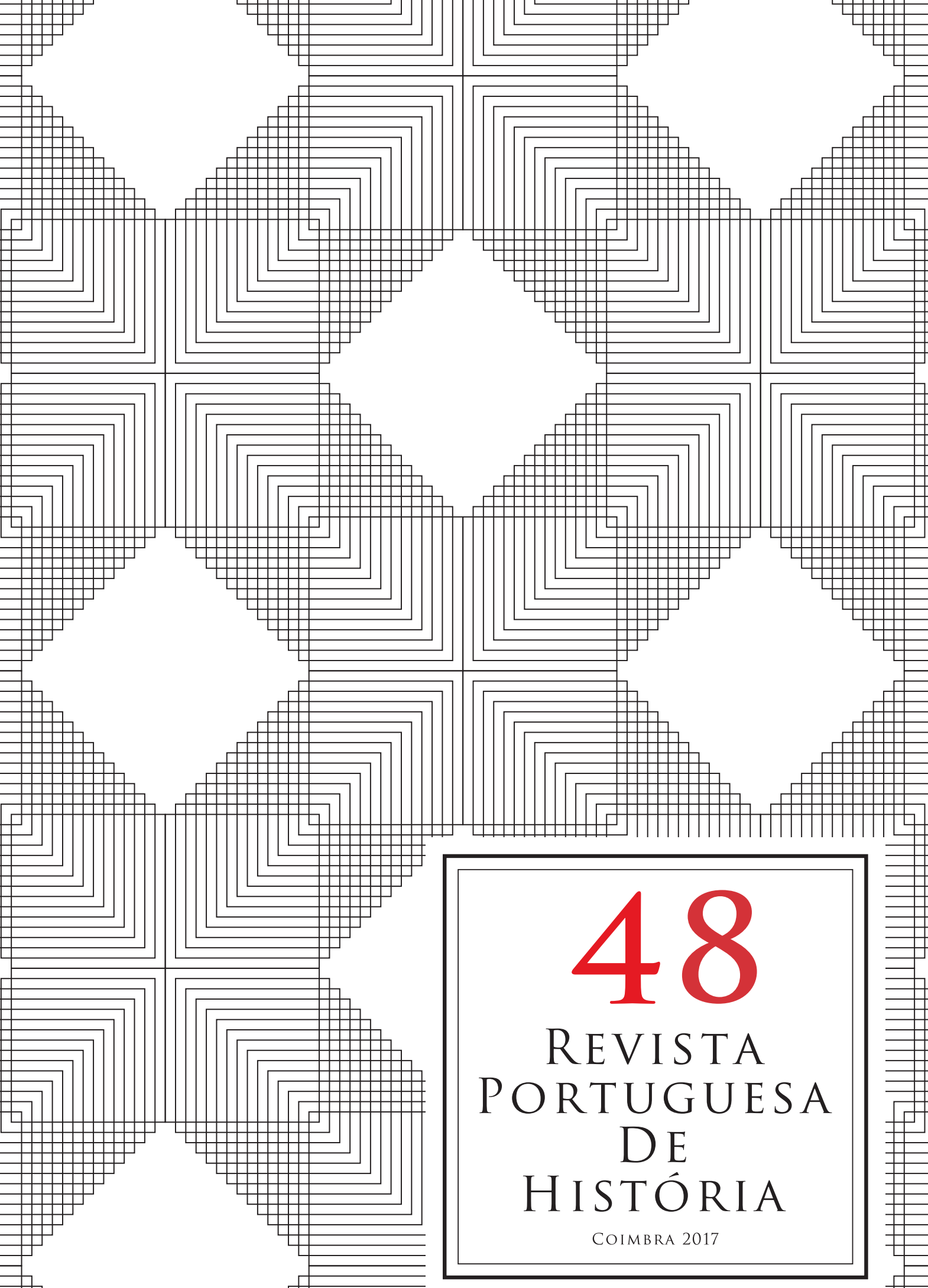




\title{
Lusofonia em perspectiva: panlusitanismo, lusobrasileirismo e lusotropicalismo
}

\author{
Lusophony in perspective: \\ panlusitanism, lusobrazilianism and lusotropicalism
}

\author{
MATEUS SILVA SKOLAUDE \\ Pontifícia Universidade Católica do RS (PUC-RS) \\ mateusskolaude@yahoo.com.br \\ MARÇAL DE MENEZES PAREDES \\ Pontifícia Universidade Católica do RS (PUC-RS) \\ marcal.paredes@pucrs.br
}

Texto recebido em/Text submitted on: 31/01/2017

Texto aprovado em/Text approved on: 11/07/2017

Resumo:

Neste artigo circunscrevemos três conceitos debatidos na perspectiva lusófona e que foram propagados entre as décadas de 1930 e 1950. O panlusitanismo do Boletim da Sociedade Luso-Africana do Rio de Janeiro que buscava a difusão ideológica das tradições lusitanas e a exaltação do vasto império colonial; o lusobrasileirismo do intelectual português Nuno Simões que defendia uma aproximação cultural fundamentada nos laços de sangue, língua e história, bem como o lusotropicalismo do ensaísta brasileiro Gilberto Freyre, que postulava uma singular capacidade de colonização dos portugueses, por conta da miscigenação e da adapção aos trópicos. Ao compreender a lusofonia enquanto perspectiva discursiva de matriz cultural, toma-se com especial interesse a configuração de escala do panlusitanismo, do lusobrasileirismo e do lusotropicalismo, ao passo que a questão central a ser analisada diz respeito a historicidade dos discursos políticos e as redes intelectuais articuladas em torno deles.
Abstract:

This paper is circumscribed within three concepts discussed through the "lusophone" perspective, which were widely propagated along the period between the 1930s and 1950s. The first concept is the "panlusitanism" present in the Luso-African Society of Rio de Janeiro bulletin that pursued the ideological dissemination of Lusitanian traditions and praised the vast colonial empire. The second concept is the "Lusobrazilianism" by the Portuguese Nuno Simões, who defended a cultural approach based on blood ties, language and history. Finally, the third concept refers to the "Lusotropicalism" by the Brazilian essayist Gilberto Freyre, who postulated a peculiar ability of Portuguese people in colonization due to miscegenation and adaptation to the tropics. Understanding "lusophony" as a discursive perspective within a cultural matrix, the configuration of "Panlusitanism", "Lusobrazilianism" and "Lusotropicalism" is taken with special interest, while the main issue to be analyzed is related to the political discourses historicity as well as the intellectual networks articulated around them. 
Palavras-chaves:

Perspectiva lusófona; Panlusitanismo; Lusobrasileirismo; Lusotropicalismo.
Keywords:

Lusophone Perspective; Panlusitanism; Lusobrazilianism; Lusotropicalism. 


\section{Introdução}

O uso do termo lusofonia abarca uma variação de significados e seu impacto político, cultural e social é consideravelmente diferenciado nos distintos países que proclamam o português como idioma oficial. Diante do caráter polissêmico, só é possível acolher a lusofonia como debate existente em torno de sua própria noção, uma noção que tem pesos muito diferenciados e que varia conforme os distintos contextos de usos e sentidos da língua portuguesa no Brasil, em Portugal e nos Países Africanos de Língua Oficial Portuguesa (PALOPs) ${ }^{1}$.

No plano da historiografia, os estudos acerca da lusofonia conferem uma certa preeminência ao lusotropicalismo ${ }^{2}$, de modo que a partir da década de 1950, o Estado Novo português utilizou-se deste referencial enquanto propaganda e política externa ${ }^{3}$. Sendo assim, o escopo lusotropical tem sido o mote investigativo de parte considerável das pesquisas na área, não obstante esta perspectiva acaba por desdenhar das redes intelectuais e da dimensão hermenêutica ${ }^{4}$ articulada em outras configurações de escala ${ }^{5}$.

Na década de 1930, quando o ensaísta Gilberto Freyre dava os primeiros passos na elaboração espistemológica do arcabouço lusotropical, ao mesmo tempo e de forma compatível, outros dois conceitos políticos eram publicizados e, em certa medida, seus articuladores representavam oposição ao regime salazarista, isto é, o panlusitanismo difundido através do boletim da Sociedade Luso-Africana do Rio de Janeiro e o lusobrasileirismo propalado pelo intelectual Nuno Simões.

${ }^{1}$ Omar Ribeiro Thomaz e Sebastião Nascimento, "Língua" in Livio Sansone e Cláudio Alves Furtado (Ed). Dicionário crítico das ciências sociais dos países de fala oficial portuguesa, Salvador, Edufba, 2014, p. 280-281.

${ }^{2}$ Adriano Moreira e José Carlos Venâncio (Ed.), Luso-Tropicalismo: Uma teoria social em questão, Lisboa, Vega, 2000.

${ }^{3}$ Sobre a utilização do "lusotropicalismo" enquanto instrumento ideológico e de propaganda colonial pelo Estado Novo português, a partir da década de 1950, consultar as obras de Cláudia Castelo. O modo português de estar no mundo: O luso tropicalismo e a ideologia colonial portuguesa (1933-1961), Porto, Afrontamento, 1998; Omar Ribeiro Thomaz, Tigres de Papel: Gilberto Freyre, Portugal e os paises africanos de lingua oficial portuguesa, in Bela Feldman-Bianco; Cristiana Bastos; Miguel Vale de Almeida (Ed), Trânsitos coloniais: diálogos críticos luso-brasileiros, Lisboa, ICS, 2013, p.47-70.

${ }^{4}$ Marçal de Menezes Paredes, A Nação e a Hermenêutica histórica ou os usos da alteridade portuguesa no horizonte de expectativa brasileiro: Da superação à condenação, in Ruth Maria Chittó Gauer (Ed.), Tempo e historicidades, Porto Alegre, Edipucrs, 2016, p. 87-108.

${ }^{5}$ Jacques Revel, "Micro-história, macro-história: o que as variações de escala ajudam a pensar em um mundo globalizado", Revista Brasileira de Educação, v. 15, n. 45, set./dez. 2010, p. 434-444. 
Neste sentido, é preciso pensarmos a lusofonia como acúmulo de camadas discursivas e de práticas sociais de construção subjetiva de uma suposta identidade cultural comum e que ao longo de diferentes temporalidades articulou dispositivos ideológicos ambivalentes. Sob este ponto de vista, os textos possuem valor analítico, no sentido da compreensão de dinâmicas históricas particulares, uma vez que em cada contexto linguístico perpassam institucionalizações discursivas que regulam o que pode ser falado. É no interior de cada contexto que se dá historicidade ao discurso, de modo que as ideias são articuladas na prática ao expressarem a construção de sentido e conhecimento de determinada intelectualidade acerca de uma dada realidade ${ }^{6}$. Valendo-se destes pressupostos, o presente artigo procura analisar a historicidade dos discursos políticos e as redes intelectuais articuladas em torno do panlusitanismo, do lusobrasileirismo e do lusotropicalismo.

\section{O Panlusitanismo da Sociedade Luso-Africana do Rio de Janeiro}

Na década de 1930, Portugal e Brasil constituíram na esfera diplomática importantes espaços de aproximação política. Se por um lado, em Portugal existia um colonialismo com pretensões nacionalistas e que pensava o exemplo brasileiro como referência às colônias africanas, por outro, no Brasil havia um nacionalismo que mobilizava componentes internacionais para com a África e para com Portugal, de modo que afirmava o contributo africano enquanto fator de civilização e rediscutia a origem portuguesa, uma vez que concebia a singularidade do português enquanto povo propenso à miscigenação?

Neste contexto, o Rio de Janeiro constituia-se no principal centro de emigração portuguesa do mundo e a colônia lusitana organizada na então Capital Federal do Brasil buscava afirmar e recriar sua identidade a partir de duas estratégias principais: o associativismo e a imprensa. Através da publicação de vários periódicos, como jornais, revistas, folhetos e almanaques, os portugueses

"As questões teórico-metodológicas articuladas partem do "contextualismo linguístico" considerando, principalmente, as contribuições de Pocock para a escrita da história intelectual. Neste estudo, adotamos a concepção de "redes intelectuais" que considera o espaço formado por um grupo de letrados que compartilham um "vocabulário", uma "retórica e um conjunto de usos" que articulam propósitos políticos, identitários e ideológicos. John G. A. Pocock, Linguagens do Ideário Político, São Paulo, Edusp, 2003, p. 63-83.

${ }^{7}$ Mateus Silva Skolaude, Raça e nação em disputa: Instituto Luso-Brasileiro de Alta Cultura, $1{ }^{a}$ Exposição Colonial Portuguesa e o $1^{\circ}$ Congresso Afro-Brasileiro (1934-1937). Tese (Doutorado em História) - Faculdade de Filosofia e Ciências Humanas, Pontifícia Universidade Católica do Rio Grande do Sul, 2016. 
conseguiam se comunicar não só com os diversos imigrantes e descendentes espalhados pelo território brasileiro, mas também com seus conterrâneos que permaneceram em Portugal ${ }^{8}$.

A visão do Brasil enquanto obra máxima da ação colonizadora portuguesa refletia-se na representação assumida pelos emigrantes residentes na antiga colônia, ao passo que a constituição da maior comunidade portuguesa fora de Portugal, em pleno século XX, reforçava simbolicamente os laços estabelecidos historicamente de uma predestinação lusitana. No dia 22 de maio de 1930 foi fundada a Sociedade Luso-Africana no Rio de Janeiro por alguns portugueses e descendentes residentes na então Capital Federal do Brasil com o lema: "Pela Raça, Pela Língua”.

A comissão diretora da entidade era formada por António de Souza Amorim, Almiro Andrade e Francisco das Dôres Gonçalves que constituíam o núcleo responsável pela organização de várias ações, entre palestras, atividades culturais, publicação de artigos, produção de materiais didáticos, organização de intercâmbio escolar e, sobretudo, pela divulgação do Boletim da Sociedade Luso-Africana ${ }^{9}$. Em 1934, a tiragem da revista era de 2.000 exemplares que eram gratuitamente distribuídos para intelectuais, políticos, além de escolas, centros culturais e prefeituras.

O periódico buscava ser um veículo articulador de todos os portugueses e descendentes espalhados pelo mundo, em especial pela aproximação política de Portugal e Brasil. Na defesa da perspectiva colonialista, a revista se instrumentalizava da representação brasileira como filho mais velho e emancipado, exemplo notório da capacidade colonizadora de Portugal que estava igualmente habilitado para reproduzir os mesmos ideais civilizatórios nas suas colônias da África, Ásia e Oceânia. Como exemplo desta postura, destaca-se um texto do ator e publicista Carlos Leal:

"O novo Brasil para os portugueses, está declaradamente, amplamente esclarecido nas nossas colónias. É no vasto império colonial português, - classificado como o terceiro do Mundo potencial [...]. Pois que tentem assaltar-nos as Colónias, e verão como é a arrancada lusíada! [...]. Pois as

\footnotetext{
${ }^{8}$ Robherta Triches. "A revista Lusitania e a colônia portuguesa do Rio de Janeiro: espaços de sociabilidade e estratégias de inserção social”, Rio de Janeiro, Unirio (Trabalho apresentado ao XIV Encontro Nacional da ANPUH-RIO, Memória e Patrimônio), 2010, p. 06. (http://www. encontro2010.rj.anpuh.org/resources/anais/8/1276649501_ARQUIVO_Anpuh2010.pdf)

${ }^{9}$ O Boletim da Sociedade Luso-Africana do Rio de Janeiro circulou entre os anos de 1931 e 1938, num total de 24 volumes que foram publicados a partir de uma periodicidade irregular. Alguns exemplares foram consultados junto ao Fundo Geral de Revistas da Biblioteca Nacional de Portugal. Cota R.E. 11291 V.
} 
Colónias Portuguesas, a mercê das várias circunstâncias do seu apreciável desenvolvimento, - formam o novo Brasil. [...] E se a Alemanha e a nobre Itália, se justificam para se assenhoriarem do que é muito nosso, - alegando que 'não sabem onde alojar os seus súditos', - que escolham outras paragens, - o deserto do Sahara comporta muita gente (...)"10.

O texto do artista português concebe a colonização brasileira como referência histórica a nova experiência colonial, uma vez que o exemplo positivo implementado na antiga colônia articulava a narrativa nacionalista da tradicional mitologia imperial, mobilizada naquele contexto como defesa frente aos interesses internacionais. Não por acaso, a mesma preocupação imperialista que rondava as colônias portuguesas na África era compartilhada por pensadores brasileiros, de modo que uma futura perda dos territórios ultramarinos por Portugal era interpretada de forma catastrófica aos futuros interesses brasileiros:

“O perigo das guerras reside na urgente expansão de alguns povos europeus. Pois evitemos os conflitos armados, atribuindo à Alemanha e à Itália, em benefício da tranquilidade geral, as partes da África que pertencem a povos impotentes para defendê-las. Com esse raciocínio primário e essa presunção gratuita o mundo estaria salvo das novas catástrofes. Se quisermos lançar os olhos sobre os horizontes do futuro brasileiro, veremos quanto importa para o Brasil que as colónias da costa ocidental do continente africano continuem sob o pavilhão dos conquistadores portugueses. Temos interesse solidário na preservação do império colonial lusitano, através de que se fará um dia a expansão do nosso país, pela identidade das origens étnicas e da língua, mantendo-se as duas margens atlânticas nas mãos de povos integrados pelas mesmas aspirações e ideais. (...) A hipótese de semelhante investida predatória contra o império lusitano na África deve encontrar da nossa parte uma resistência estrêma, pois que ligado ao destino daquelas ribas do continente negro, mais do que poderiam imaginar os espíritos descuidosos, está a projecção futura do Brasil como potência mundial". ${ }^{11}$

O texto de Austregésilo de Athayde mobilizava numa leitura essencialista da lusitanidade elementos agregadores de uma identidade histórica com interesses comuns. O mito imperial de perspectiva pluricontinental constituía-se na língua

${ }^{10}$ Carlos Leal, “Alerta!”, Boletim da Sociedade Luso-Africana do Rio de Janeiro, n. 5 (Abril, Maio, Junho) de 1933, p. 69-70.

${ }^{11}$ Austregésilo de Athayde, "Vizinhaça Cartaginesa", Boletim da Sociedade Luso-Africana do Rio de Janeiro, $\mathrm{n}^{\circ}$ 16/17 (Janeiro a Junho) de 1936, p. 128. 
e na etnicidade conforme alguns aspectos de elevado simbolismo presentes nos discursos do Boletim da Sociedade Luso-Africana do Rio de Janeiro. O editorial da revista publicado em 1934 também reflete esta conduta:

\section{"Realizações"}

"Hoje como ontem, a mesma confiança, o mesmo entusiasmo, a mesma vontade de realizar e o mesmo empenho de servir a causa do pan-lusitanismo nos dão o forte alento com que batemos os altos e saudáveis caminhos do optimismo (...) movidos pelo desejo, que é o nosso orgulho, de realizarmos uma propaganda do Império Português (...). Estamos, todavia, muito longe de nos dar por satisfeitos com o que já realizamos, que representa algo para a insignificância dos nossos recursos mas quási nada para o que temos planeado, e que é, para já, ou seja, para a nossa gestão: um "Boletim" especial, expressamente dedicado a Exposição Colonial do Pôrto, uma série de conferências pelos mais altos expoentes e mais legítimos representantes da inteligência e da cultura portuguesa no Brasil e a edição de uma Cartilha Colonial da autoria do insigne poeta e escritor Capitão Augusto Casimiro destinada a todas as escolas da língua portuguesa, dispersas pelo Mundo!" 12

O texto assinado por um dos editores chefes da revista, Francisco das Dôres Gonçalves pode ser divido em duas partes. Na primeira, o autor mobilizou como tema principal o papel desempenhado em quatro anos pela Sociedade Luso-Africana do Rio de Janeiro na propagação do panlusitanismo. Esta perspectiva ideológica representava o mote editorial da revista, tendo em vista a instrumentalização pedagógica na defesa de uma tradição secular do grande império e das tradições portuguesas. Na segunda parte do texto, Gonçalves estabeleceu dois projetos para serem realizados em um curto prazo, isto é, a publicação de uma cartilha colonial para ser distribuída em escolas de língua portuguesa e a edição de um número especial da revista que seria referente a $1^{\mathrm{a}}$ Exposição Colonial Portuguesa. Os dois projetos elaborados por Francisco das Dôres Gonçalves foram concretizados, ou seja, o número especial da revista relacionada a 1. ${ }^{\text {a }}$ Exposição Colonial Portuguesa ${ }^{13}$ e a cartilha pedagógica ${ }^{14}$. Poucos meses depois do anúncio oficial, o boletim comemorativo já circulava

${ }^{12}$ Francisco das Dôres Gonçalvez, "Realizações", Boletim da Sociedade Luso-Africana do Rio de Janeiro, $n^{\circ} 8$ (Janeiro, Fevereiro, Março), 1934, p. 1-2.

${ }^{13}$ Omar Ribeiro Thomaz, Ecos do Atlântico Sul: representações sobre o terceiro império português, Rio de Janeiro, Editora UFRJ/Fapesp, 2002, p. 192-271.

${ }^{14}$ Boletim da Sociedade Luso-Africana do Rio de Janeiro. Número Especial Comemorativo da Exposição Colonial Portuguesa realizada no Porto, $n^{\circ}$ 9, abril-junho de 1934, p. 161. Outra reportagem sobre a Cartilha Colonial encontra-se no Boletim da Sociedade Luso-Africana do Rio de Janeiro, $\mathrm{n}^{\circ} 10$ e 11 segunda série, agosto e dezembro de 1934, p. 64. 
como veículo de propaganda no Brasil e em Portugal. Neste número, os responsáveis pela editoração da revista procuravam realçar a exposição enquanto um meio de aproximação política de Portugal e Brasil, o aspecto simbólico estabelecido pelo jogo de cores da capa deixa claro esta tentativa ${ }^{15}$.

$\mathrm{Na}$ articulação dos boletins era necessário que a Sociedade Luso-Africana mantivesse a colaboração de muitos apoiadores que seriam os responsáveis por prepararem artigos, entrevistas e reportagens que retratassem temas como: história, língua, cultura, política e os domínios ultramarinos. Contudo, se havia comunhão na interpretação e a na projeção lusíada do Império Ultramarino, no que tange à posição política assumida por estes intelectuais, nem sempre se percebe a mesma convergência com a política ideológica implementada pelo Estado Novo português. Em 1936, a Sociedade Luso-Africana é acusada por autoridades consulares de divulgação contrária ao salazarismo por conta do envolvimento político com figuras ligadas ao republicanismo português, tendo, inclusive, recebido resposta negativa a uma solicitação de ajuda para a realização da Semana do Ultramar no Rio de Janeiro ${ }^{16}$.

\section{O lusobrasileirismo de Nuno Simões}

O Brasil sempre foi o destino preferencial da emigração portuguesa e o refúgio de muitos dissidentes dos diversos governos de Portugal. A partir do advento da ditadura em 1926, o território brasileiro passou a receber opositores ao regime que foram acolhidos pelos compatriotas e companheiros políticos ${ }^{17}$. A Sociedade Luso-Africana mantinha um forte vínculo com figuras políticas ligadas a Primeira República portuguesa (1910-1926) e que representavam oposição ao regime salazarista.

Entre os letrados correspondentes do boletim destaca-se o papel desempenhado pelo Gen. Norton de Matos (1867-1955), patrono da entidade. Em 1932, a Sociedade Luso-Africana encaminhou um protesto em solidariedade ao militar quando do seu retorno a Portugal ${ }^{18}$. Norton de Matos obteve papel de

${ }^{15}$ Mateus Silva Skolaude, Raça e Nação em disputa, cit., p. 138.

${ }^{16}$ Heloísa Paulo e Armando B. Malheiro da Silva, "Norton de Matos, o Brasil e as raízes do paraíso: a construção da colônia ideal e o ideal colonialista" in Maria Bernadete Ramos; Élio Serpa e Heloísa Paulo (Ed.). O beijo através do Atlântico: O lugar do Brasil no Panlusitanismo, Chapecó, Argos, 2001, p. 322-323.

${ }^{17}$ Heloísa Paulo, "O exílio português no Brasil: Os 'Budas' e a oposição antisalazarista", Portuguese Studies Review, 14 (2), 2006/7, p.126-127.

${ }^{18}$ Heloísa Paulo e Armando B. Malheiro da.Silva, "Norton de Matos, o Brasil...", cit., p. $357-422$. 
destaque durante o período republicano ao ocupar diversos cargos públicos, entre eles foi governador (1912 e 1915) e alto-comissário (1921 a 1924) de Angola, além de Ministro das Colônias (1915) e embaixador em Londres (1924-1926). Adversário político da ditadura salazarista, Norton de Matos apresentou sua candidatura à presidência da República nas eleições de 1948, juntando à sua volta um núcleo de resistência ao regime.

Assim como Norton de Matos, outro importante interlocutor da Sociedade Luso-Africana do Rio de Janeiro foi Nuno Simões (1894-1976), sócio honorário da entidade, com participação de destaque em muitas edições da revista e que teve sua foto exposta em um quadro na sede da entidade, em homenagem aos inúmeros serviços prestados ${ }^{19}$. Jornalista e economista, Simões também ocupou diversos cargos públicos no período republicano, entre eles foi Governador, Deputado e Ministro do Comércio e das Comunicações ${ }^{20}$.

Norton de Matos e Nuno Simões recebiam em Portugal todos os boletins da Sociedade Luso-Africana publicados no Brasil. Além da revista, os representantes encaminhavam junto alguns livros lançados na ex-colônia, como por exemplo a obra Raizes do Brasil do historiador Sérgio Buarque de Holanda que foi enviada ao ex-governador de Angola ${ }^{21}$. O pensamento de Norton de Matos não fugia a regra geral do pensamento colonialista português, uma vez que buscava no passado mítico da colonização brasileira uma experiência positiva para a construção de um império colonial na África.

Nuno Simões era adepto confesso da política de desenvolvimento implementada por Norton de Matos na África e ambos eram responsáveis pela divulgação da Sociedade Luso-Africana em Portugal, de modo que também distribuíam alguns exemplares da revista entre associações, políticos e intelectuais lusitanos ${ }^{22}$. Nuno Simões escreveu muitos textos em Portugal legitimando o protagonismo militante articulado pela Sociedade Luso-Africana no Brasil:

\footnotetext{
${ }^{19}$ Boletim da Sociedade Luso-Africana do Rio de Janeiro, n. ${ }^{\circ} 10$ e 11 segunda série, agosto e dezembro de 1934, p. 253.

${ }^{20}$ Arminda Ferreira, O Luso-Brasileirismo: Na perspectiva de Nuno Simões, Famalicão, Quasi, 2005.

${ }^{21}$ Heloísa Paulo e Armando B. Malheiro da Silva, Norton de Matos, o Brasil... cit., p. 311-312 .

${ }^{22}$ Em carta assinada pelo Sr. A. R. Almeida Santos e endereçada ao Diretor da Sociedade Luso-Africana do Rio de Janeiro, o remetente parabenizou a entidade brasileira pelo Boletim especial relacionado a 1. ${ }^{\text {a }}$ Exposição Colonial Portuguesa. No documento, o autor afirmou que recebeu a revista do ilustre amigo e antigo parlamentar Dr. Nuno Simões. Boletim da Sociedade Luso-Africana do Rio de Janeiro, n. ${ }^{\circ} 10$ e 11 segunda série, agosto e dezembro de 1934, Sessão Depoimentos, p. 234.
} 


\begin{abstract}
"Obreiros da Unidade Portuguesa"
“(...) Abriu a Exposição Colonial do Porto um ciclo propício à relação e à exaltação de toda a nossa obra colonial. Há que lembrar, ao tratar-se desta, todos os que, por pensamentos palavras e obras, a têm servido. Entre os que, nos últimos tempos, se voltaram a esse alto objetivo a Sociedade Luso-Africana tem um lugar primacial. Vivem as pequenas nações continentais europeias que são grandes no mundo um momento difícil. Voltam-se para os domínios de Portugal atenções suspeitas e cobiças que já não sabem dissimular-se. Precisamos como nunca de fortalecer a consciência do nosso destino histórico e de demonstrar o sentido profundo e indestrutível da nossa unidade moral, política e econômica. A isso vem a Exposição Colonial. A isso visa a acção da Sociedade Luso-Africana que precisamos não esquecer que exerce a sua actvidade admirável em um país de 42 milhões de habitantes que falam a nossa língua e que justamente reivindicam a sua hegemonia moral e política na América do Sul (...) E esse testemunho não o fará o Brasil apenas servindo a fraternidade que nos une, quando pensar que no litoral do Atlântico Sul, fronteira à sua grandeza e prosperidade, fica uma das porções maiores, mais ricas, mais povoadas e mais portuguesas do nosso Ultramar e que não pode ser-lhe indiferente que nela vivam e se perpetuem povos da mesma origem comum, com a mesma missão civilizadora e pacífica e com o mesmo fraterno anseio de engrandecimento moral da raça e da humanidade"23
\end{abstract}

Percebe-se na introdução do excerto anterior que Nuno Simões fez uma breve saudação à $1^{\text {a }}$ Exposição Colonial Portuguesa enquanto um espaço importante de mobilização da história e de defesa do grande império colonial. A posição assumida foi bastante discreta se comparada a de outros intelectuais, de modo que não houve enaltecimento aos idealizadores e nem mesmo as principais referências políticas do Estado Novo. Esta atitude reflete um rancor de Simões pois teria sido ele o idealizador da exposição - mas que, por sua discordância quanto ao caráter oficial da mesma e de sua oposição ao regime, acabou por ser preterido da coordenação dos trabalhos. Este ressentimento pode ser percebido através de um outro artigo publicado por Nuno Simões no Primeiro de Janeiro, um ano após o encerramento da exposição ${ }^{24}$.

Ao mesmo tempo, verifica-se que Nuno Simões não poupou palavras na legitimação daquilo que considerava ser o mais relevante, isto é, apoiar iniciativas de caráter precursor, como o exemplo proporcionado pela Sociedade

${ }^{23}$ Nuno Simões, "Obreiros da Unidade Portuguesa", Primeiro de Janeiro, 29/06/1934 in Nuno Simões, Portugueses no mundo: Esboço para um estudo e notas de uma campanha, Vila Nova de Famalicão, Minerva, 1940, p. 162-163.

${ }^{24}$ Nuno Simões, "Exposição da expansão porguesa", Primeiro de Janeiro, 30 de outubro de 1935 in Nuno Simões, Portugueses no mundo...cit, p. 330. 
Luso-Africana enquanto promotora de um espírito fraternal ${ }^{25}$ no Brasil e em Portugal. Diante disso, citou a legitimidade da iniciativa, tendo em vista a origem comum e o destino histórico nas diferentes regiões de uma mesma tradição lusitana.

Numa perspectiva militante, Simões apelou para o fortalecimento desta sociedade enquanto um projeto pioneiro e com grande capacidade de crescimento. Além disso, colocou o Brasil numa posição de protagonista nesta relação civilizadora, levando em conta a propagação da raça numa perspetiva transnacional das regiões de colonização portuguesa. Nuno Simões constituía-se num intelectual com forte penetração política entre os Diretores da Sociedade Luso-Africana do Rio de Janeiro, ao passo que era admirador confesso da perscpetiva panlusitanista defendida pelos seus ideólogos e na esteira deste pensamento constituíu-se num ferrenho defensor do lusobrasileirismo que, nas suas próprias palavras, era definido como: "Um ideário de aproximação cultural, fundamentada nos laços de sangue, de língua, tradições, história e amizade comum dos dois países, de modo que dentro de cada sociedade, brasileira e portuguesa, permaneça uma base de unanimidade, coordenação e motivação perante as relações econômicas, políticas, sociais e culturais" ${ }^{\prime 26}$.

Simões, em diferentes temporalidades e através de diversos meios de comunicação, militou em defesa do lusobrasileirismo. Neste caso, destacou-se no engajamento junto a Revista Atlântida no período pós Primeira Guerra Mundial, ao declarar que havia chegado o momento de formatação de uma grande articulação "lusoafrobrasileira"27. Na década de 1930, além de interlocutor da Sociedade Luso-Africana, Nuno Simões representava um importante correspondente de intelectuais brasileiros em Portugal, sobretudo, de Gilberto Freyre.

Além disso, a condição assumida por Nuno Simões de colocar o Brasil numa posição de protagonista nas relações transnacionais junto as colônias portuguesas na África se encaixava perfeitamente ao projeto pessoal que Gilberto Freyre almejava alcançar na década de 1930, haja vista a criação de um instituto de

${ }^{25}$ Marçal de Menezes Paredes, Configurações Luso-Brasileiras: Fronteiras Culturais, Demarcações da História e Escalas Identitárias (1870-1910), Saarbruken, Novas Edições Acadêmicas, 2013.

${ }^{26}$ Arminda Ferreira, O luso-brasileirismo... cit, p. 12-13.

${ }^{27}$ Sílvio Marcus de Souza Corrêa, "O "perigo alemão" nas fronteiras do "mundo luso-afro-brasileiro"” in Marçal de Menezes Paredes (Ed.), Portugal, Brasil, África: história, identidades e fronteiras, São Leopoldo, Oikos, 2012, p. 142. 
pesquisas na África, projeto articulado pelo ensaísta pernambucano e que foi debatido e encaminhando nos bastidores do $1^{\circ}$ Congresso Afro-Brasileiro ${ }^{28}$.

\section{Ensaio Lusotropical de Gilberto Freyre}

Nuno Simões por duas vezes escreveu no Primeiro de Janeiro sobre Gilberto Freyre e o $1^{\circ}$ Congresso Afro-Brasileiro, organizado no Recife em novembro de 1934. Na ocasião, nomeou os respectivos artigos conforme o título dos anais publicados respectivamente em 1935 e 1937: Estudos Afro-Brasileiros ${ }^{29}$ e Novos Estudos Brasileiros ${ }^{30}$. O $1^{\circ}$ Congresso Afro-Brasileiro também foi objeto de apreciação em duas páginas do boletim da Sociedade Luso-Africana do Rio de Janeiro, organizado três meses após a finalização da exposição portuguesa. Nas páginas da revista foi noticiado que o Presidente Francisco das Dôres Gonçalves emitiu um telegrama louvando a iniciativa e os organizadores do encontro ${ }^{31}$. Gilberto Freyre principal idealizador, assim como outros intelectuais que participaram do congresso, também publicaram textos no boletim da Sociedade Luso-Africana ${ }^{32}$.

Nas páginas da revista, Casa Grande \& Senzala foi objeto de uma recensão de três páginas escrita pelo padre português Manuel Alves Correia. O missionário assim adjetivou a obra: "o livro de Gilberto Freyre é notabilíssimo. O público, tanta vez caprichoso, desta vez foi bem advertido e tomou conta da importância da obra: a primeira edição é de 1933; esgotou-se rapidamente; tenho presente a

${ }^{28}$ Sobre o $1 .{ }^{\circ}$ Congresso Afro-Brasileiro e o projeto pessoal de Gilberto Freyre em relação a organização deste evento, ver Mateus Skolaude, Raça e Nação ... cit., p. 185-211.

${ }^{29}$ Nuno Simões, "Estudos Afro-Brasileiros", O Primeiro de Janeiro, 19/06/1936, capa.

${ }^{30}$ Nuno Simões, "Novos Estudos Brasileiros", O Primeiro de Janeiro, 30/04/1937, capa. Este mesmo artigo foi publicado no Brasil, três meses e meio depois, no Jornal Diário de Pernambuco, 25/07/1937, p. 3 e 9 da segunda seção.

31 "Congresso Afro-Brasileiro", Boletim da Sociedade Luso-Africana do Rio de Janeiro, n. ${ }^{\circ} 10$ e 11 segunda série, agosto e dezembro de 1934, p. 250-251.

${ }^{32}$ Gilberto Freyre publicou na revista o texto: "Sugestões para o Estudo da Arte Brasileira com a de Portugal e a das Colónias", p. 7-8. Este artigo é uma síntese de um dos artigos publicado no livro: "Conferências na Europa". Além deste, a revista publicou "Levantes de negros no Brasil" de Arthur Ramos (p.15-16); "O negro e a cultura no Brasil” de Renato Mendonça, p. 34-35. "O problema das raças" de Edison Carneiro, p. 37-38; "A superstição da côr preta” de Mário de Andrade, p. 49-50. Todos os artigos aqui citados encontram-se publicados na última edição da revista Boletim da Sociedade Luso-Africana do Rio de Janeiro, n. ${ }^{\circ}$ 24, dezembro de 1938. 
segunda, de 1936. Duas edições em tão curto prazo, neste género de literatura, constituem felicidade rara" 33 .

Nas décadas de 1930 e 40, a tese desenvolvida por Gilberto Freyre sobre a plasticidade portuguesa e a influência miscigenada na cultura brasileira foi recebida de forma ambivalente em Portugal. Se por um lado, parte considerável do meio intelectual recebeu de forma positiva as teses gilbertianas, por outro, no campo político, o Estado Novo português sob o prisma do darwinismo social ${ }^{14}$ rejeitou implicitamente a obra de Freyre, sobretudo, pela importância que o autor conferiu à mestiçagem, à interpenetração de culturas, à herança moura e africana na gênese do povo português e das sociedades criadas pela colonização lusa ${ }^{35}$.

O posicionamento intelectual assumido por Freyre era objeto constante de correspondências diplomáticas. No dia 13 de agosto de 1942, o Cônsul Português em Pernambuco, Manuel Anselmo endereçou ao Presidente do Conselho e Ministro dos Negócios Estrangeiros, Antônio de Oliveira Salazar, um ofício ${ }^{36}$ criticando a postura "comunista e antilusitana" do escritor, por conta de um artigo publicado no Diário de Pernambuco no dia 11 de agosto de 1942 com o título: "A propósito da unificação da ortografia" 37 .

Nove meses depois, no dia 30 de abril de 1943, o Cônsul enviou um outro ofício ao Embaixador Português no Rio de Janeiro (Sr. Martinho Nobre de Mello) onde manifesta insatisfação com a organização da I Quinzena do Livro Português que deveria ter sido realizada no Recife. Neste documento, Anselmo nomeou o escritor Jaime Cortesão de "traidor" e Gilberto Freyre de "nocivo", ambos "representantes das esquerdas no Brasil e opositores ao Governo de Salazar"

Todavia, na década de 1950, no período pós Segunda Guerra Mundial, a necessidade do governo português em afirmar a unidade nacional perante as pressões externas favoráveis a autodeterminação das colônias, condicionou

${ }^{33}$ Manuel Alves Correia (Missionário de Espírito Santo), "Gilberto Freyre - Casa Grande e Senzala”, Boletim da Sociedade Luso-Africana do Rio de Janeiro, no 22-23, julho a dezembro de 1937, p. 72-74.

${ }^{34}$ Ana Leonor Pereira, Darwin em Portugal: Filosofia, História, Engenharia Social (1865-1914), Coimbra, Almedina, 2001.

${ }^{35}$ Cláudia Castelo, $O$ modo português... cit, p. 80.

${ }^{36}$ Arquivo Histórico Diplomático Português, Ministério dos Negócios Estrangeiros, Repartição dos Negócios Políticos Processo: 38, Assunto: Relações culturais com o Brasil, 2. ${ }^{\circ}$ Piso, Arm. 48, Maço: 233.

${ }^{37}$ Gilberto Freyre, "A propósito da unificação da ortografia”, Jornal Diário de Pernambuco, agosto de 1942, p. 04.

${ }^{38}$ Arquivo Histórico Diplomático Português... cit. 
o lusotropicalismo enquanto discurso oficial do governo salazarista. O lusotropicalismo caracterizaria uma suposta imunidade dos portugueses ao racismo, a sua predisposição a mestiçagem, diferentemente dos outros povos europeus, assim como sua plasticidade e vocação ecumênica.

Este conceito teria sido elaborado e manifestado primeiramente por Gilberto Freyre no início da década de 1950, em conferências que foram organizadas no livro: Um brasileiro em terras portuguesas (1953). Entretanto, as formulações centrais da teoria lusotropicalista já se encontravam em dois textos estruturais da década de 1930, isto é, Casa Grande \& Senzala (1933) e Conferências na Europa $(1938)^{39}$.

Conferência na Europa reuniu quatro palestras que foram apresentadas na Inglaterra e em Portugal, sendo que três delas foram lidas em Lisboa, Porto e Coimbra, em setembro de 1937. Naquela ocasião, a viagem de Gilberto Freyre a Portugal foi chancelada pelo governo brasileiro e marcada por um caráter oficial, mas por conta de um problema de saúde familiar, Freyre antecipou o retorno ao Brasil. Em meio a curta estadia na cidade de Lisboa, Gilberto Freyre concedeu uma extensa entrevista ao Primeiro de Janeiro. Entre os intelectuais portugueses que Gilberto Freyre mencionou na entrevista destaca "a cooperação do Dr. Nuno Simões, que não tenho ainda o prazer de conhecer pessoalmente, mas a quem devo mais de uma prova de simpatia e mais de um artigo generoso no 'Primeiro de Janeiro' e no 'Diabo' "'40.

Muito provavelmente a própria entrevista de Gilberto Freyre ao Primeiro de Janeiro teria sido articulada por Nuno Simões. Contudo, a curta estadia de Freyre em Portugal não permitiu que os dois realizassem um importante projeto, isto é, escreverem juntos um ensaio sobre o vinho do Porto, estudo semelhante ao que Freyre havia desenvolvido sobre a cana de açúcar no Nordeste Brasileiro $^{41}$. A memória de Gilberto Freyre anos mais tarde representa um importante testemunho:

"Nuno Simões - repito - já desejou muito que eu tentasse, com ele, um estudo da região do vinho do Porto: estudo semelhante ao que cheguei a esboçar

${ }^{39}$ Cláudia Castelo, "Uma incursão no lusotropicalismo de Gilberto Freyre", Blogue de História Lusófona, ano VI, 2011a, p. 267-269 (http://www2.iict.pt/archive/doc/bHL_Ano_ VI_16_Claudia_Castelo_Uma_incursao_no_lusotropicalismo.pdf)

${ }^{40}$ O Primeiro de Janeiro, 02/08/1937, p. 02.

${ }^{41}$ O livro Nordeste, publicado em 1937, apresenta uma ideia geral da civilização açucareira e da sociedade patriarcal, de modo a enfatizar a importância das relações entre a natureza e a sociedade. Gilberto Freyre, Nordeste: Aspectos da Influência da Cana sobre a Vida e a Paisagem do Nordeste do Brasil, São Paulo, Global Editora, 2013. 
da região brasileira mais antiga da cana de açúcar, nas páginas de Nordeste. Essa aventura de colaboração até hoje não a conseguimos sequer iniciar. Nem ao menos as vindimas pudemos ver juntos, em 37: o ano marcado para o início do nosso estudo"42

Com o passar dos anos, Freyre e Simões fortaleceram os laços de amizade. De toda a gama de intelectuais portugueses que o brasileiro se contactou, Nuno Simões foi o segundo com quem mais se correspondeu (53 cartas), atrás apenas do crítico literário Luís Forjaz Trigueiros ( 95 cartas) e a frente do político e sociólogo Adriano Moreira (30 correspondências) $)^{43}$.

Conferências na Europa diferentemente de Casa Grande \& Senzala estendia o objeto de análise do Brasil para todas as áreas de colonização portuguesa. A partir desta publicação, Gilberto Freyre transpôs o estudo de caso brasileiro ao conjunto de territórios lusófonos, isto é, o Brasil, a África e a Ásia portuguesa constituiriam uma unidade de sentimento e cultura. O caráter atribuído por Freyre na legitimação imaginária do devir lusotropical e os pressupostos históricos mobilizados pelo autor na definição deste conceito aparecem de forma categórica no texto: "Aspectos da influencia da mestiçagem sobre as relações sociais e de cultura entre portugueses e luso-descendentes".

Já no primeiro parágrafo chamou a atenção para o fato de que os portugueses teriam sido colonizadores "mais brandos", propensos à miscigenação com gentes de cor habitantes dos trópicos, devido a um conjunto de fatores de ordem religiosa, geográfica, histórico e cultural. Estas tendências teriam se disseminado por praticamente todo o império colonial português, constituindo nestas regiões uma democracia social com "unidade de sentimento e cultura" 4 .

A perspectiva assumida por Freyre também carregava no caráter biológico elementos centrais na definição do português, enquanto um povo indefinido em relação aos padrões tradicionais europeus. Neste caso, o escritor entendia a raça do ponto de vista neolamarckista ${ }^{45}$, enquanto concepção baseada na aptidão do homem para se adaptar a diferentes condições ambientais, assim como para incorporar e transmitir as características resultantes da interação com o meio.

${ }^{42}$ Gilberto Freyre, Aventura e rotina: Sugestões de uma viagem a procura das constantes portuguesas de caráter e ação, Rio de Janeiro, Editora José Olympio, 1953, p. 197.

${ }^{43}$ Cláudia Castelo, "Leituras da correspondência de portugueses para Gilberto Freyre", Actas do VI Congresso Luso-Afro-Brasileiro de Ciências Sociais: As Ciências Sociais nos Espaços de Língua Portuguesa: Balanços e Desafios, vol. 2, Porto, FLUP, 2000, p. 423.

${ }^{44}$ Gilberto Freyre, Conferências na Europa, Rio de Janeiro, Ministério da Educação e Saúde, 1938, p. 07.

${ }^{45}$ Ricardo Benzaquen de Araújo, Guerra e Paz: Casa Grande \& Senzala e a obra de Gilberto Freyre nos anos 30, Rio de Janeiro, Editora 34, 1994. 
Esta indefinição étnica do português se apresentava para Freyre como estrutura fundante nos trópicos, tendo em vista a necessidade de contato e mistura com o diferente, no caso especificamente brasileiro, num primeiro momento com o indígena nativo e depois com o negro africano ${ }^{46}$

A miscigenação estabelecida por portugueses com índios e negros teria resolvido um dos impasses centrais para a colonização portuguesa no Brasil, qual seja: a escassez populacional. Tratadas dessa maneira, Freyre justificou que o português teria uma predisposição para a colonização híbrida em decorrência de seu passado de povo indefinido entre a Europa e a África. A forte miscigenação praticada na península Ibérica povoada por judeus, celtas, africanos, mouros, além das próprias populações nativas, aliada à proximidade geográfica e climática com a África teria favorecido o êxito da colonização portuguesa nos trópicos. Com essa tese, o escritor compreendia que não apenas no Brasil haveria a formação de uma nova "raça histórica" ${ }^{77}$ produto da especial adaptação lusitana às terras e às gentes dos trópicos, mas o próprio tronco luso seria uma "raça histórica" para o qual concorreu uma variedade imensa de grupos étnicos culturais.

A partir disto, Freyre compreendia que a ascensão social de elementos culturais provenientes dos mais diferentes grupos só foi possível frente a singular colonização brasileira, ou seja, ao se entregarem à luxúria com índias e negras, os portugueses teriam estabelecido outro aspecto democratizador nas relações étnicas do Brasil. O inverso, por exemplo, do que aconteceu na formação da América espanhola e dos ingleses na colonização da América do Norte. Segundo Freyre, a escravidão africana se diluiu na obra criadora e original portuguesa, uma vez que a miscigenação em larga escala teria suavizado as fronteiras econômicas e raciais entre senhores e escravos ${ }^{48}$

A perspectiva familiar segue para Freyre, o mesmo padrão de entendimento, uma vez que as relações interétnicas e a consequente mestiçagem teriam possibilitado o amor incondicional do patriarca com mulheres e filhos, independentemente de questões raciais. Se, por um lado, o escritor considerou que dentro deste universo familiar emergiu um ambiente de abrandamento dos rigores morais, por outro, declarou ser inegável que em alguns casos, estas relações não se deram de forma romântica, mas com marcas da extrema violência do homem branco com mulheres índias e negras ${ }^{49}$.

\footnotetext{
${ }^{46}$ Gilberto Freyre, Conferências ... cit., p. 08.

${ }^{47}$ Omar Ribeiro Thomaz, Tigres de Papel... cit, p. 58-59.

${ }^{48}$ Gilberto Freyre, Conferências ... cit, p. 08-09

${ }^{49}$ Gilberto Freyre, Conferências ... cit, p. 09-10.
} 
Para Freyre é no seio da família patriarcal que se estabeleceu o amalgama das culturas, sendo que a raça era enfocada em termos psicológicos e enquanto predisposição capaz de atuar no processo de mestiçagem. Ao mesmo tempo, o escritor celebrava o cruzamento dos três grupos étnico-culturais da formação brasileira, subvertendo a pretensa hierarquia racial de superioridade "branca". Para ele, a miscigenação estabelecida nas relações entre senhores e escravos teria amolecido o conflito, amortizado o racismo e constituído um processo completamente inovador, mas que até então se constituía enquanto objeto de calúnia ${ }^{50}$.

$\mathrm{O}$ valor atribuído por Gilberto Freyre às relações sexuais entre os diferentes grupos étnico-raciais formadores do Brasil explica, em grande parte, o perfil da colonização portuguesa nos trópicos. Se valendo desta ideia, Freyre compreendia que a formação híbrida diluía fronteiras raciais, ao passo que desdenhava do racismo enquanto algo estrutural na sociedade brasileira. Ao justificar positivamente a mestiçagem propagada pelo português, o autor reconhecia neste empreendimento uma conduta civilizadora e eticamente superior a qualquer outra, uma vez que estes fatores conjugados teriam conduzido o Brasil há uma política voltada à assimilação e à democracia social ${ }^{51}$.

Valendo-se do conceito elaborado por Giddings, Gilberto Freyre identificava nos povos de colonização portuguesa um sentimento supranacional denominado de "consciência de espécie" 52 . A mestiçagem neste caso era reconhecida pelo autor como um elemento comum em todas as regiões e, ao mesmo tempo, um vetor estrutural de negação do racismo e da pureza étnica. Essa consciência, porém, não anulava as diferenças culturais regionais e essa realidade aparentemente paradoxal entre a parte e o todo tenderia ao equilíbrio ${ }^{53}$.

Ao tomar a mestiçagem como categoria articuladora de um sentimento comum e transnacional existente nas colônias portuguesas, Gilberto Freyre acreditava que as múltiplas expressões regionais se amalgamavam numa escala mais ampla da cultura nos territórios de colonização portuguesa. A perspectiva assumida por Gilberto buscava afirmar uma posição intelectual do autor em relação à mobilização da história, a partir de pretensos pressupostos culturais que anos mais tarde legitimou-se enquanto um conceito político a serviço ideológico do Estado Novo português e que foi batizado de lusotropicalismo.

${ }^{50}$ Gilberto Freyre, Conferências ... cit, p. 11-12.

${ }^{51}$ Gilberto Freyre, Conferências ... cit, p. 14.

${ }^{52}$ Maria Lucia Garcia Pallares-Burke, Gilberto Freyre: Um vitoriano dos trópicos, São Paulo, Editora da UNESP, 2005, p. 373.

${ }^{53}$ Gilberto Freyre, Conferências ... cit, p. 19. 


\section{Considerações finais}

Depois de cruzadas as três perspetivas relativas à lusofonia, se torna claro que as redes intelectuais constituídas em torno da Sociedade Luso-Africana, bem como o caráter relacional e os aspectos intertextuais do panlusitanismo e do lusobrasileirismo acabavam por determinar em projetos defendidos nos dois lados do atlântico. Não por acaso, nos parece interessante que as posições ideológicas articuladas na década de 1930 por Nuno Simões e pelos ideólogos e colaboradores da Sociedade Luso-Africana, em muitos aspectos, iam ao encontro a perspectiva lusotropical ensaiada teoricamente por Gilberto Freyre no mesmo contexto, mas que somente ganhou status político e científico duas décadas mais tarde.

Ao compactuarmos deste entendimento, consideramos que o princípio regulatório do lusotropicalismo não pode ser compreendido, única e exclusivamente, pelo marco fronteiriço de autoria e temporalidade, ou como sugere Martins: "o que aqui se emancipa pode, ali, num outro contexto, manifestar propriedades de constrangimento, e que o contrário é também possível" ${ }^{54}$.

Colocando em perspectiva as três categorias discutidas neste artigo, fica patente a importância de compreender as nuances contextuais travadas em torno do próprio conceito. A pesquisa histórica e sobretudo, um olhar atento à historicidade dos significados ajudam a desenssencialiar pensamentos e ter atenção aos desafios políticos que contemporaneamente remobilizam a lusofonia como estratégia da política global.

${ }^{54}$ Rui Cunha Martins, "O paradoxo da demarcação emancipatória: a fronteira na era da sua reprodutibilidade icónica", Revista Crítica de Ciências Sociais, Coimbra, n. 59, fevereiro 2001, p. 50. 